\title{
Gastroduodenal intussusception secondary to a gastric lipoma
}

\author{
Fausto Y Vinces DO, Joseph Ciacci DO, David C Sperling MD, Steven Epstein MD
}

\begin{abstract}
FY Vinces, J Ciacci, DC Sperling, S Epstein. Gastroduodenal intussusception secondary to a gastric lipoma. Can J Gastroenterol 2005;19(2):107-108.
\end{abstract}

\begin{abstract}
Gastroduodenal intussusception caused by a gastric lipoma is an uncommon condition, and only a few cases have been reported in the medical literature. A case of a 72-year-old man who complained of weight loss and intermittent episodes of nausea and vomiting is presented. Diagnostic workup demonstrated a mass in the second portion of the duodenum. The patient underwent a diagnostic laparoscopy followed by an exploratory laparotomy that confirmed the gastroduodenal intussusception by a gastric lipoma. In addition, the anatomical and clinical presentation, diagnosis and management of this entity are discussed.
\end{abstract}

Key Words: Gastric lipoma; Gastroduodenal; Intussusception

\section{Invagination gastroduodénale, secondaire à un lipome gastrique}

Le lipome gastrique donne rarement lieu à une invagination gastroduodénale, et la documentation médicale ne fait état que de quelques cas. Voici le cas d'un homme de 72 ans qui a consulté pour une perte de poids et des épisodes intermittents de nausées et de vomissements. Les examens de diagnostic ont révélé une masse dans la deuxième partie du duodénum. Le patient a subi une laparoscopie diagnostique, suivie d'une laparoscopie exploratoire qui a confirmé la présence d'une invagination gastroduodénale causée par un lipome gastrique. Il sera également question des aspects anatomiques, du tableau clinique, du diagnostic et du traitement de cet état pathologique.
G astroduodenal intussusception is an extremely rare cliniCal entity; it is reported to be the least frequent type of intussusception involving the gastrointestinal tract (1). The lead point of the intussusception is usually a benign gastric tumour (2). The majority of cases are caused by adenomas, with only a small number caused by lipomas (1). We present a unique case of gastroduodenal intussusception due to a submucosal lipoma of the stomach, presenting as intermittent gastric outlet obstruction. The clinical presentation, diagnosis and management of this entity are discussed. To our knowledge, only eight cases of gastroduodenal intussusception caused by a gastric lipoma have been reported in the medical literature (3).

\section{CASE PRESENTATION}

A 72-year-old man presented with a six-month history of heartburn, epigastric pain, weight loss and regurgitation of food. Six days before admission, the patient was unable to keep any food down and became dehydrated. His physical examination was unremarkable for masses, tenderness or peritoneal signs. His laboratory data substantiated his dehydration but was otherwise unhelpful.

A plain abdomen x-ray demonstrated a distended stomach without any other abnormal pattern. A computed tomography (CT) scan of the abdomen demonstrated a low attenuation, intraluminal tumour, providing some indication of a gastroduodenal intussusception (Figure 1). Because of the patient's stability, an upper gastrointestinal endoscopy was performed and demonstrated a submucosal mass at the antrum level that made cannulation of the first portion of the duodenum extremely difficult. Biopsies taken from this area showed only normal mucosa.

A diagnostic laparoscopy was performed and demonstrated a mass at the antral level. This was followed by a formal exploratory laparotomy that confirmed the presence of a large antral mass that had intussuscepted into the second portion of the duodenum. The intussusception was reduced by applying pressure to its apex, and the mass was reduced through the pyloric sphincter. Gastrotomy was performed and revealed a submucosal lipoma measuring $5 \mathrm{~cm} \times 6 \mathrm{~cm}$. The lesion was excised and the gastrotomy was closed in two layers. The pathology report was consistent with a lipoma. Postoperatively, the patient made an uneventful recovery and was discharged on postoperative day 6 . He was followed up in the surgical clinic up to six weeks after his procedure and remains asymptomatic.

\section{DISCUSSION}

Chiarri made the first report of a gastroduodenal intussusception in 1888 (4). Gastroduodenal intussusception is usually secondary to a benign or, rarely, a malignant tumour (1). Polyps constitute $40 \%$, intramural smooth muscle tumours constitute another $40 \%$ and benign lesions comprise the remaining $20 \%$ (1). Gastric lipomas account for only $5 \%$ of all gastrointestinal lipomas and are usually seen in the body or antrum of the stomach (3). They rarely present as an intussusception. However, cases of gastric outlet obstruction and upper gastrointestinal bleeding have been reported $(5,6)$.

Department of Surgery, Saint Barnabas Hospital, Bronx, New York, USA

Correspondence and reprints: Fausto Y Vinces DO, Saint Barnabas Hospital, Department of Surgery, Third Avenue and 183rd Street, Bronx,

New York 10457, USA. Telephone 718-960-6127, fax 718-960-6132, e-mail vincesf@optonline.net

Received for publication January 21, 2004. Accepted September 9, 2004 


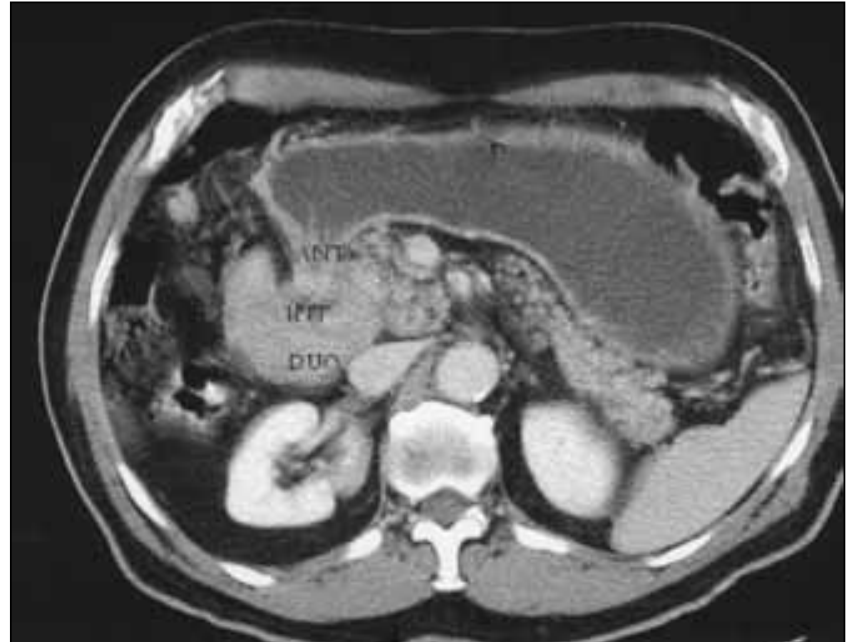

Figure 1) Contrast-enhanced axial computed tomography showing narrowing of the antrum (ANT) before the formation of the intussusception (INT) into the first and second portion of the duodenum (DUO)

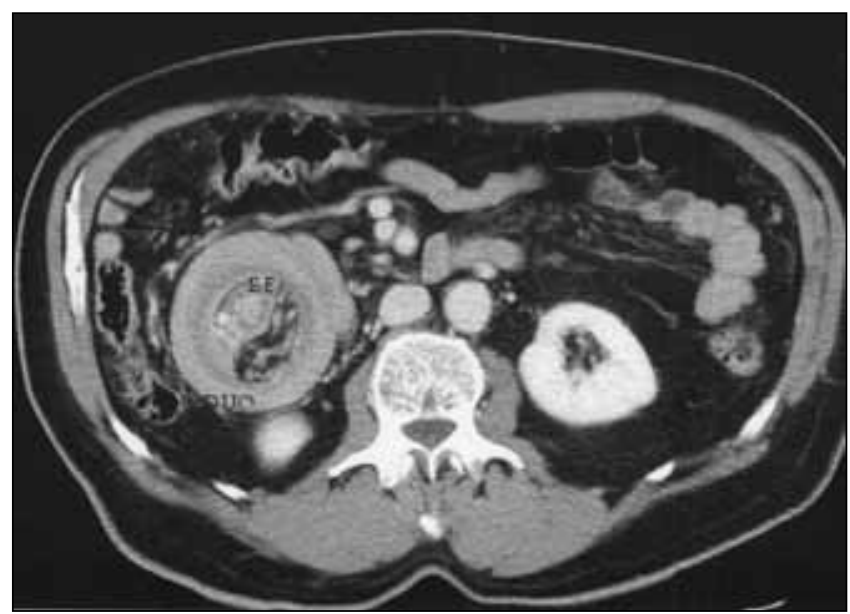

Figure 2) Classic 'target' or 'bull's eye' (BE) appearance of the intussusception. DUO Duodenum

The lead point of the gastroduodenal intussusception is nearly always a pedunculated, benign gastric tumour. Gastroduodenal intussusception is rare because of the anatomical fixity of the cardia and pylorus of the stomach and duodenum. Because of this fixity, the possibility of intussusception between these structures is decreased. It is believed that defective mesenteric fixation or relaxation of the restraining ligament attachments play a role in the pathogenesis of this condition (2).

Diagnosis can be made preoperatively by upper gastrointestinal series or CT. CT with oral contrast revealed a wellcircumscribed, submucosal lesion with uniform fat attenuation and the classic 'target' or 'bull's eye' (Figures 2 and 3). Upper gastrointestinal endoscopy is useful in cases where patients are hemodynamically stable. Endoscopic signs that help differentiate lipomas from other tumours include the 'pillow' or 'cushion' sign and the 'tenting' sign characterized by the ease with which the overlying mucosa can be lifted (1).

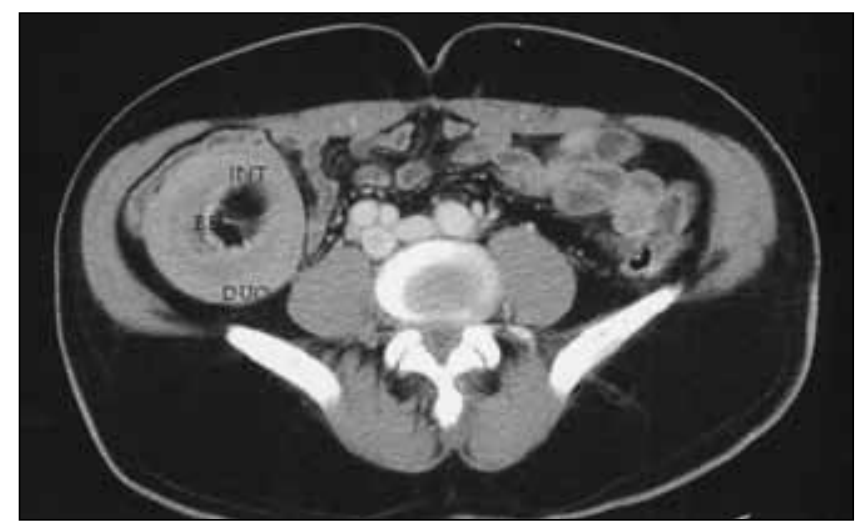

Figure 3) Extension of the intussusception (INT) into the second portion of the duodenum (DUO) with the 'bull's eye' (BE) sign

The treatment is excision, which can be performed endoscopically if the lipoma is pedunculated or smaller than $6 \mathrm{~cm}$ in diameter (7). Laparoscopy is another alternative suitable for some patients. A gastrotomy is made and the tumour is everted and excised. The gastrotomy is closed by a stapled technique (8). However, the treatment of choice is a laparotomy with excision of the lipoma through a gastrotomy. The possibility of a partial gastrectomy should be considered if the size of the lipoma does not allow a formal excision.

\section{CONCLUSIONS}

Gastroduodenal intussusception caused by gastric lipomas is an extremely rare clinical entity. The presentation can vary from asymptomatic cases to gastric outlet obstruction or bleeding. The diagnosis is usually made by CT, upper gastrointestinal series or upper endoscopy in hemodynamically stable patients. However, in cases associated with complications such as bleeding or intussusception, or where preoperative diagnosis is not confirmed, a laparotomy with local excision of the lipoma is required.

\section{REFERENCES}

1. Sankaranunni B, Ooi DS, Sircar T, Smith RC, Barry J. Gastric lipoma causing gastroduodenal intussusception. Int J Clin Pract 2001;55:731-2.

2. Lin F, Setya V, Signor W. Gastroduodenal intussusception secondary to a gastric lipoma: A case report and review of the literature. Am Surg 1992;58:772-4.

3. Moues CM, Steenvoorde P, Viersma JH, van Groningen K, de Bruine JF. Jejunal Intussusception of a gastric lipoma: A review of literature. Dig Surg 2002;19:418-20.

4. Fernandez MJ, Davis RP, Nora PF. Gastrointestinal lipomas. Arch Surg 1983;118:1081-3.

5. Myint M, Atten MJ, Attar BM, Nadimpalli V. Gastric lipoma with severe hemorrhage. Am J Gastroenterol 1996;91:811-2.

6. Bijlani RS, Kulkarni VM, Shahani RB, Shah HK, Dalvi A, Samsi AB. Gastric lipoma presenting as obstruction and hematemesis. J Postgrad Med 1993;39:42-3.

7. Nakamura S, Iida M, Suekane H, Matsui T, Yao T, Fujishima M. Endoscopic removal of gastric lipoma: Diagnostic value of endoscopic ultrasonography. Am J Gastroenterol 1991;86:619-21.

8. Treska V, Pesek M, Kreuzberg B, Chudacek Z, Ludvikova M, Topolcan O. Gastric lipoma presenting as upper gastrointestinal obstruction. J Gastroenterol 1998;33:716-9. 


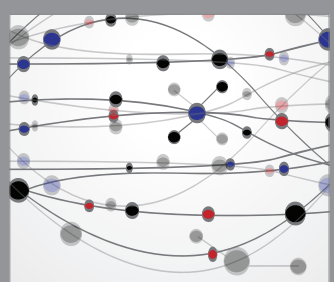

The Scientific World Journal
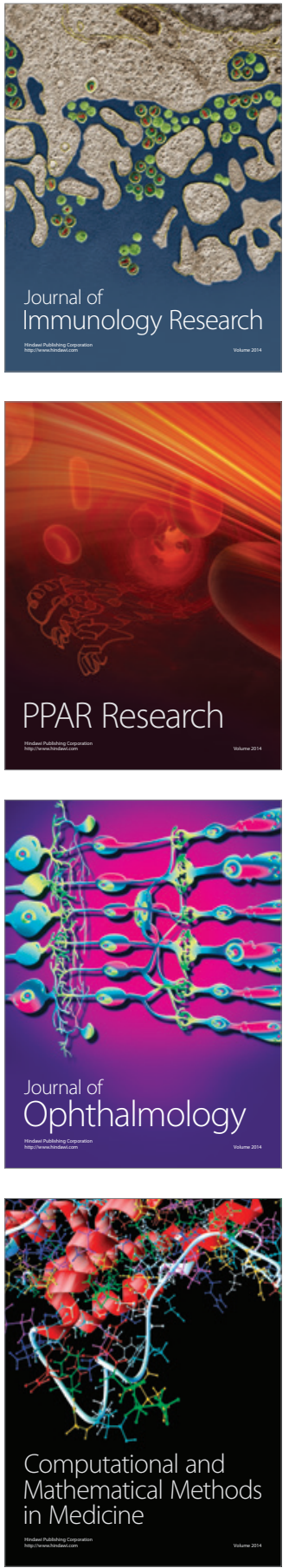

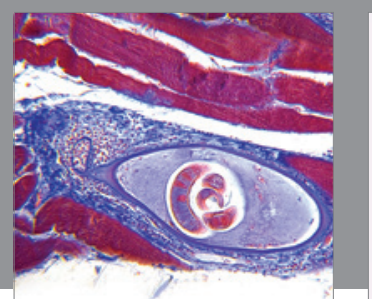

Gastroenterology Research and Practice

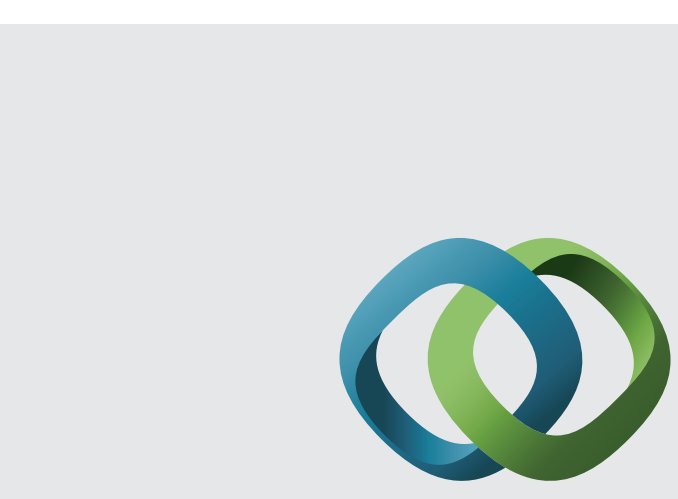

\section{Hindawi}

Submit your manuscripts at

http://www.hindawi.com
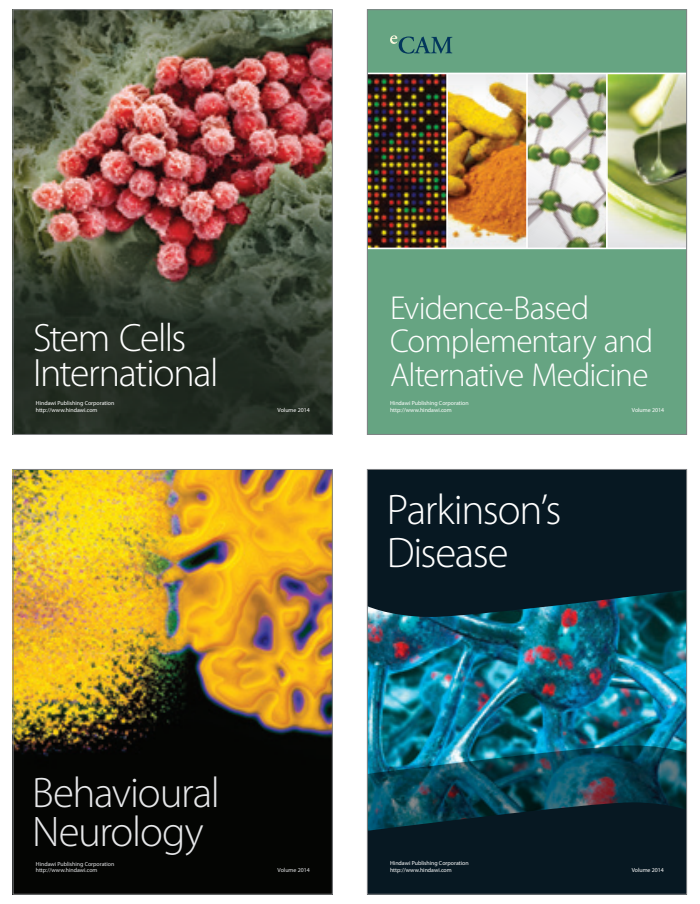
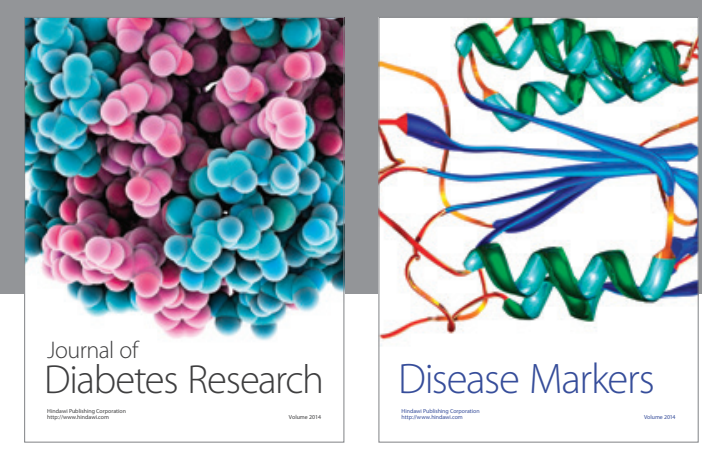

Disease Markers
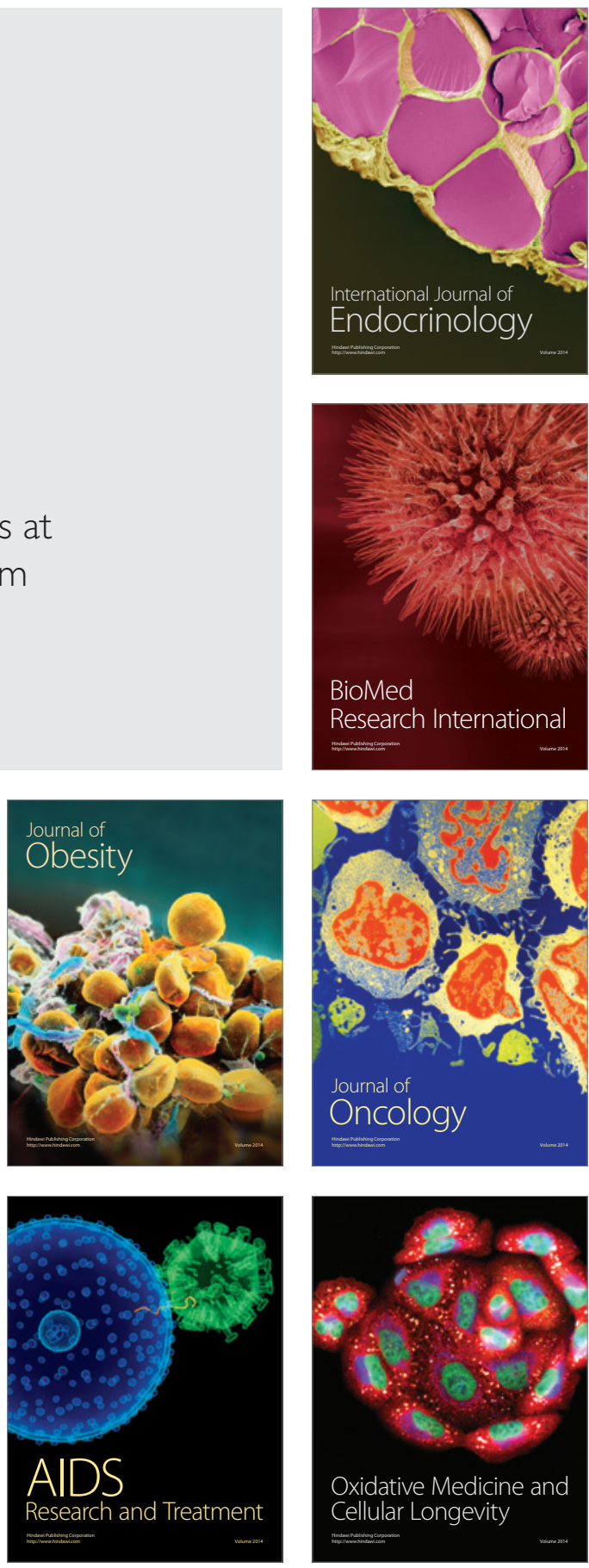